\title{
MODELAGEM E SIMULAÇÃO DE HIDROCICLONES INDUSTRIAIS PARA A SEPARAÇÃO DE ALUMINA/LICOR
}

\author{
P. L. BARROS ${ }^{1}$, J. J. N. ALVES ${ }^{1}$, F. S. LIMA ${ }^{1}$ e V. M. C. ALVES ${ }^{1}$ \\ ${ }^{1}$ Universidade Federal de Campina Grande, Departamento de Engenharia Química \\ E-mail para contato: plinsbarros@gmail.com
}

\begin{abstract}
RESUMO - O estudo de hidrociclones é motivado por serem alternativas eficientes e econômicas na indústria para a separação de partículas. Hidrociclones são equipamentos utilizados em processos de separação líquido-sólido, e particularmente na separação da alumina do licor caustico no processo de produção de alumina. Neste trabalho o processo de separação de alumina e licor cáustico em hidrociclones industriais foi modelado e simulado com o objetivo de prever e maximizar eficiência global e individual de separação. Utilizou-se o modelo Euleriano-Euleriano, com o modelo de turbulência SST para a fase contínua, implementados no software ANSYS CFX. Os resultados previstos de eficiência de separação foram validados com dados industriais de uma planta de produção de alumina.
\end{abstract}

\section{INTRODUÇÃO}

Hidrociclones são utilizados em processos físicos de separação líquido-sólido baseado na diferença de densidade evidenciada pela força centrífuga aplicada ao sistema. As partículas sólidas são direcionadas à parede, movem descendentemente por meio de uma trajetória circular e são recuperadas pela base do equipamento (underflow) enquanto o líquido, menos denso, é recuperado pelo topo do hidrociclone (overflow).

À medida que os hidrociclones auxiliaram na separação mecânica de partículas sólidas dispersas de uma suspensão, foram encontradas aplicações principalmente em indústrias minerais, químicas e farmacêuticas (Stephens, 2009). Eles surgiram como uma alternativa eficiente e econômica na separação de partículas por motivos como: menor custo de manutenção, não possuir partes móveis, simplicidade de operação e pouco espaço para instalação. Outra comparação com outros dispositivos de separação mecânica que corrobora o uso de hidrociclones como alternativa mais barata, é a necessidade unicamente de energia para superar a queda de pressão encontrada durante a operação (Schuetz et al., 2004).

Classicamente, a separação das partículas é compreendida e governada através do balanço da força centrífuga, responsável pelo direcionamento de partículas sólidas à parede do hidrociclone, somada ao balanço da força de arrasto, responsável pelo direcionamento do fluido menos denso ao topo do equipamento (Cullivan et al., 2004). 


\subsection{Parâmetros}

A eficiência de separação de um hidrociclone depende basicamente de dois fatores: a geometria do equipamento e das condições físico-operacionais. No que diz respeito à geometria, são observadas combinações específicas de modelo para cada finalidade (Wang e Yu, 2006). Dentre os parâmetros geométricos que exercem uma maior influência no desempenho desses equipamentos são: diâmetro do hidrociclone, diâmetro de vortex-finder, área da abertura de entrada, diâmetro do apex e ângulo do cone. A Figura 1 mostra cada um destes. Por outro lado, os parâmetros físico-operacionais observados com relação à eficiência são: pressão, vazão, concentração de sólidos na alimentação e distribuição granulométrica das partículas na alimentação.

\subsubsection{Eficiência Total e Granulométrica}

Para a compreensão efetiva de como os parâmetros citados anteriormente são determinantes para eficiência, é necessária a explanação de como é tratada esta última. Sabendo que as partículas de interesse encontram-se recolhidas no underflow, a eficiência total de separação é determinada como sendo o quociente entre a vazão mássica de sólido na base do equipamento e a vazão mássica total de sólidos alimentados, como apresentado na Equação 1.

$$
E_{T}=\frac{W_{u}}{W_{a}}
$$

À medida que se deseja obter o desempenho do hidrociclone para cada diâmetro de partícula, analisa-se a eficiência granulométrica. Esta é definida como sendo a razão entre as vazões mássicas de sólido no underflow pela alimentação, como apresentado na Equação 2, neste caso para um determinado tamanho de partícula, requerendo a análise granulométrica de sólidos na entrada.

$$
E_{G}=E_{T} \frac{d X_{u}}{d X_{a}}
$$

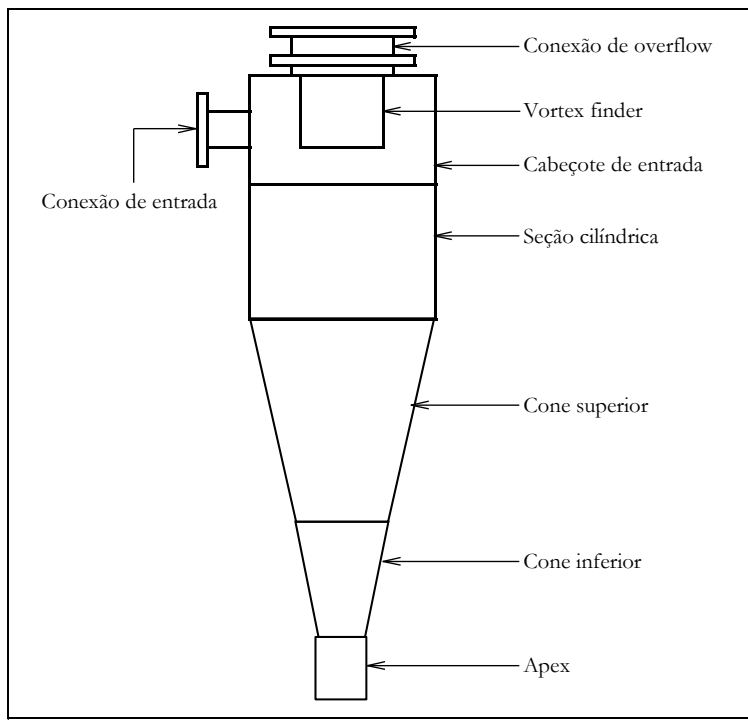

Figura 1 - Parâmetros geométricos do hidrociclone. 


\subsection{Separação de Alumina e Licor}

É abordado neste trabalho a utilização de hidrociclones para a classificação de hidratos em uma indústria de produção de alumínio, localizada na área de precipitação da refinaria composta por 11 precipitadores, onde o underflow do último deles é direcionado aos hidrociclones. Nesta área objetiva-se recolher a alumina precipitada, contida em licor rico em aluminato, na forma de hidrato $\left(\mathrm{Al}_{2} \mathrm{O}_{3} \cdot 3 \mathrm{H}_{2} \mathrm{O}\right)$.

Segundo Silva (2006), a produção de alumínio requer sólidos com determinado tamanho de partícula, resistência ao atrito e pureza ao sair da calcinação, sendo esta última o processo posterior à separação mecânica realizada pelo hidrociclone. Portanto, o equipamento em estudo objetiva a separação da alumina contida no licor, além da classificação de sólidos.

\section{CASO ESTUDADO E METODOLOGIA}

A implementação do processo de separação em hidrociclone foi realizada pelo software Ansys CFX. Tendo como etapas de execução a criação da geometria, geração da malha, determinação de condições operacionais, modelos de resolução e obtenção de resultados.

\subsection{Geometria e Malha}

A geometria do hidrociclone foi efetivada tendo como dimensões as de um industrial fornecido pela Netzch AKW Equipamentos e Processos de modelo RWT 4118. A Figura 2 ilustra as cotas do corpo deste equipamento.

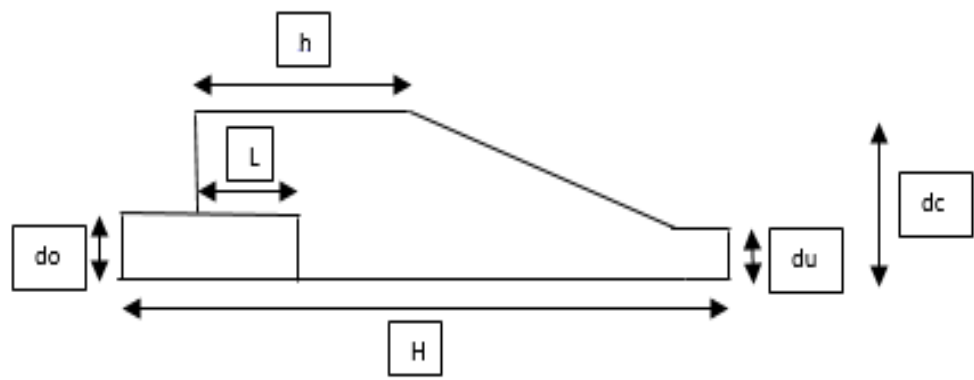

Figura 2 - Cotas do hidrociclone industrial analisado. (2006)

A Tabela 1 relaciona, quantitativamente, as cotas ilustradas na Figura 2 extraído de Silva

Tabela 1 - Dimensões do hidrociclone industrial analisado

\begin{tabular}{|c|c|c|c|c|c|}
\hline $\mathbf{H}(\mathbf{m})$ & $\mathbf{h}(\mathbf{m})$ & do $(\mathbf{m})$ & $\mathbf{d u}(\mathbf{m})$ & $\mathbf{d c}(\mathbf{m})$ & $\mathbf{L}(\mathbf{m})$ \\
\hline 1,176 & 0,420 & 0,0325 & 0,024 & 0,1015 & 0,1580 \\
\hline
\end{tabular}

Após a geração da base do corpo do hidrociclone, foi determinado o posicionamento da entrada para alimentação do equipamento, de forma que fosse direcionada tangencialmente, intensificando a ação da força centrífuga no sistema. 
Foi gerada uma malha tetraédrica não estruturada para o estudo atual, com refinamentos nas paredes, por meio de inflações, e próximo a junção de partes sólidas, obtendo uma quantidade de 914134 nós e 531489 elementos.

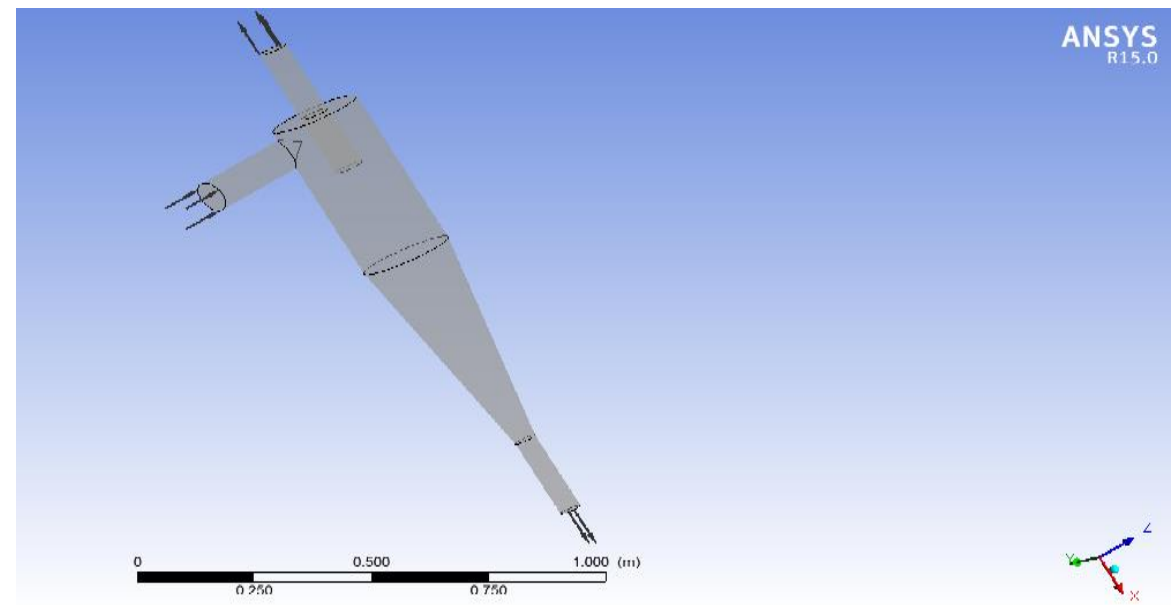

Figura 3 - Representação esquemática do equipamento em estudo.

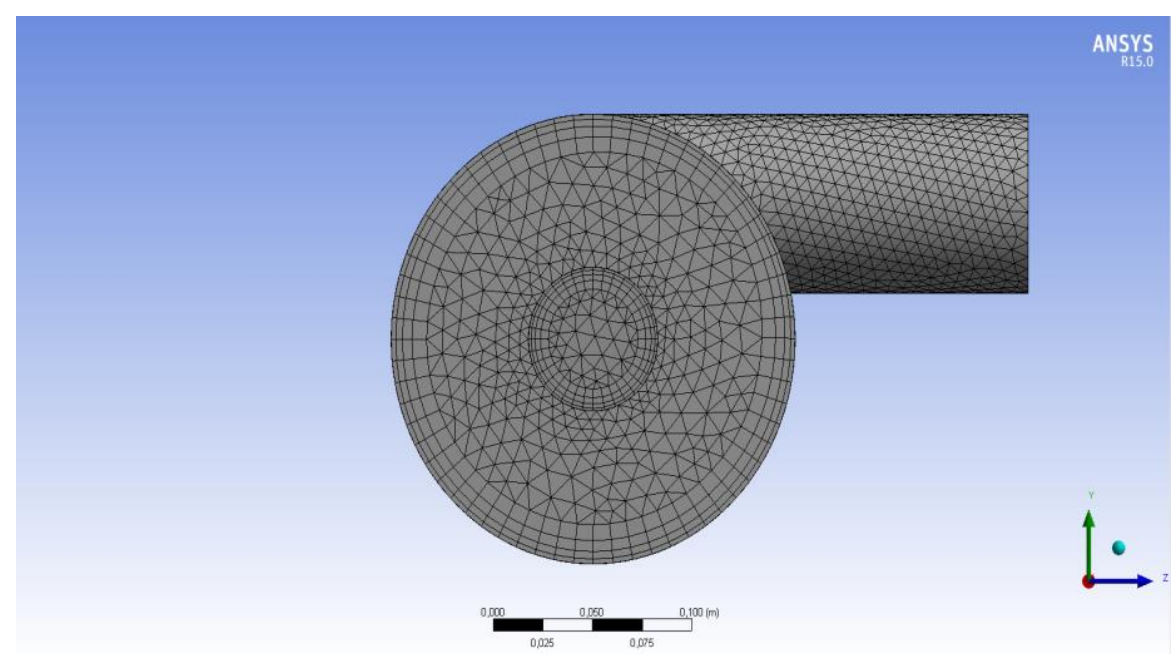

Figura 4 - Representação da malha gerada em visão superior.

\subsection{Condições operacionais e modelos de resolução}

Foram simulados 6 testes com o intuito de apurar o desempenho do hidrociclone em estudo em meio a diferentes condições operacionais. Para tanto, a concentração de alumina na alimentação foi variada entre $324 \mathrm{~g} / \mathrm{l}$ a $424 \mathrm{~g} / \mathrm{l}$, alterando ao mesmo tempo a vazão e a pressão na entrada. A Tabela 2 apresenta as condições de contorno aplicadas à simulação. Silva (2006) apresentou a análise granulométrica na alimentação, utilizada para a determinação da eficiência de separação individual de partículas sólidas de alumina.

Utilizou-se o modelo Euleriano-Euleriano em estado estacionário, sendo o licor cáustico, de densidade $1310 \mathrm{Kg} / \mathrm{m}^{3}$, a fase contínua e a alumina, de densidade $2420 \mathrm{Kg} / \mathrm{m}^{3}$, caracterizando a fase dispersa com diâmetros variando entre 20 e $124 \mu \mathrm{m}$. O sistema de separação foi considerado isotérmico, determinando o modelo de turbulência Shear Stress Transport (SST) com correção de curvatura para a fase contínua e um modelo invíscido ao sistema particulado. 
Foram também consideradas as saídas expostas igualmente à pressão atmosférica. Para método de resolução, foi utilizado o Upwind de primeira ordem associado à um critério de convergência de $10^{-5}$.

Tabela 2 - Condições de contorno

\begin{tabular}{|c|c|c|c|c|c|}
\hline Teste & Pressão $(\mathrm{kPa})$ & $\mathrm{C}_{\mathrm{a}}(\mathrm{gpl})$ & $\mathrm{Q}_{\mathrm{a}}(\mathrm{Kg} / \mathrm{s})$ & $\mathrm{X}_{\mathrm{s}}$ & $\mathrm{X}_{1}$ \\
\hline $\mathrm{A}$ & 169,6 & 410 & 26,7986 & 0,1694 & 0,8306 \\
\hline $\mathrm{B}$ & 169,6 & 424 & 27,8747 & 0,1752 & 0,8248 \\
\hline C & 179,6 & 345 & 27,7335 & 0,1426 & 0,8574 \\
\hline $\mathrm{D}$ & 173,7 & 324 & 24,3507 & 0,1339 & 0,8661 \\
\hline E & 177,6 & 366 & 25,7807 & 0,1512 & 0,8488 \\
\hline F & 179,2 & 333 & 25,5979 & 0,1376 & 0,8624 \\
\hline
\end{tabular}

\section{RESULTADOS}

Foram obtidos perfis de variáveis como pressão, velocidade superficial e fração volumétrica de cada fase. São apresentados neste trabalho os perfis referentes ao teste A.

Como previsto, a Figura 5 mostra uma maior pressão nas paredes decrescendo progressivamente em direção ao centro, tendo em vista que a velocidade e a fração molar de sólidos próximo à parede é maior devido à ação da força centrífuga, ratificado pelas Figuras 6 e 7, que mostram perfis de fração volumétrica.

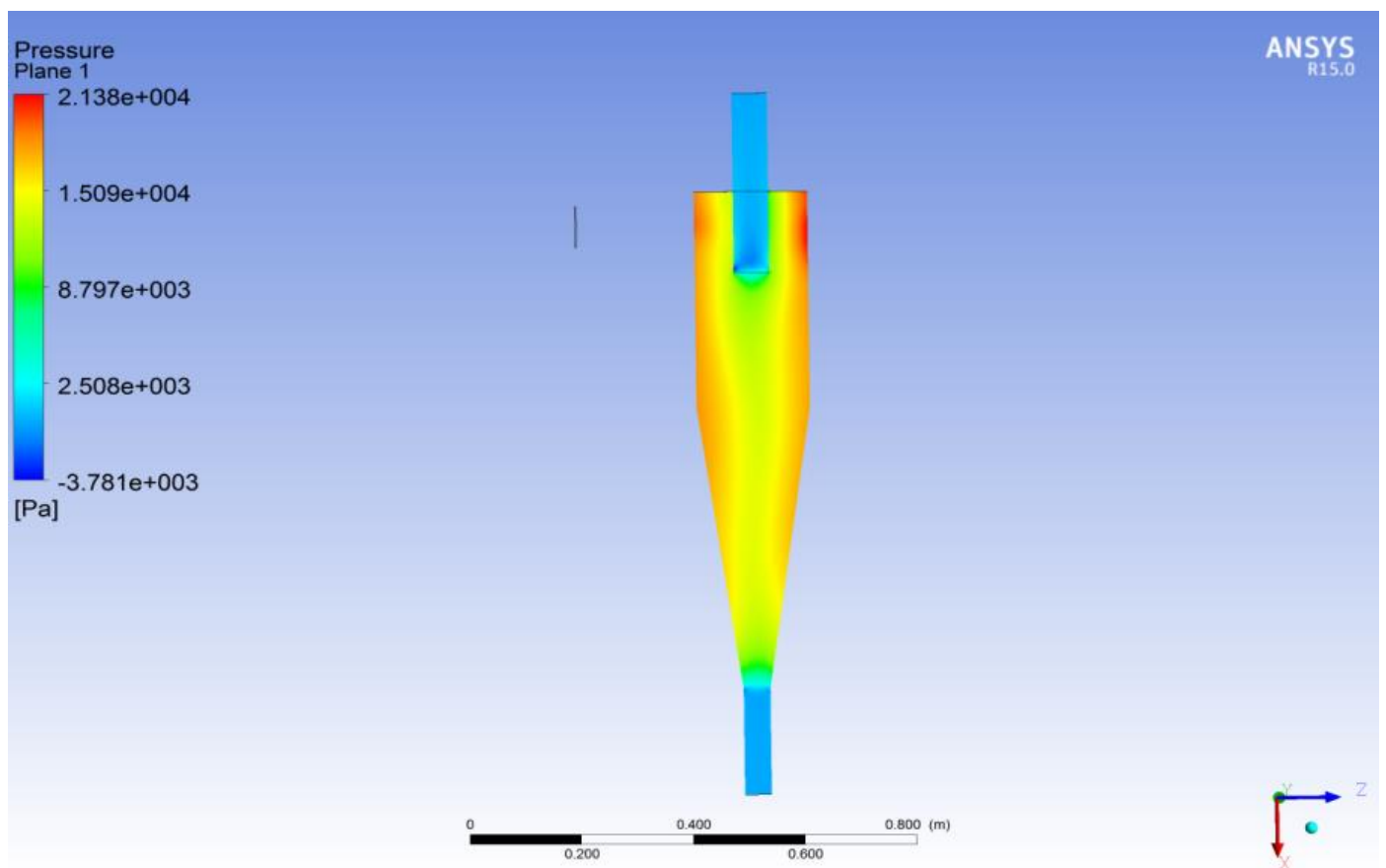

Figura 5 - Perfil de pressão.

Verifica-se na Figura 8 uma velocidade maior do sólido próximo à parede do equipamento. Isto ocorre devido à superposição da força centrífuga sobre o sólido em 
detrimento da força de arrasto. Também pode ser observada a presença de vetores de velocidade no topo do hidrociclone, caracterizado pela ineficiência do equipamento associadas à partículas sólidas finas de alumina na saída de topo.

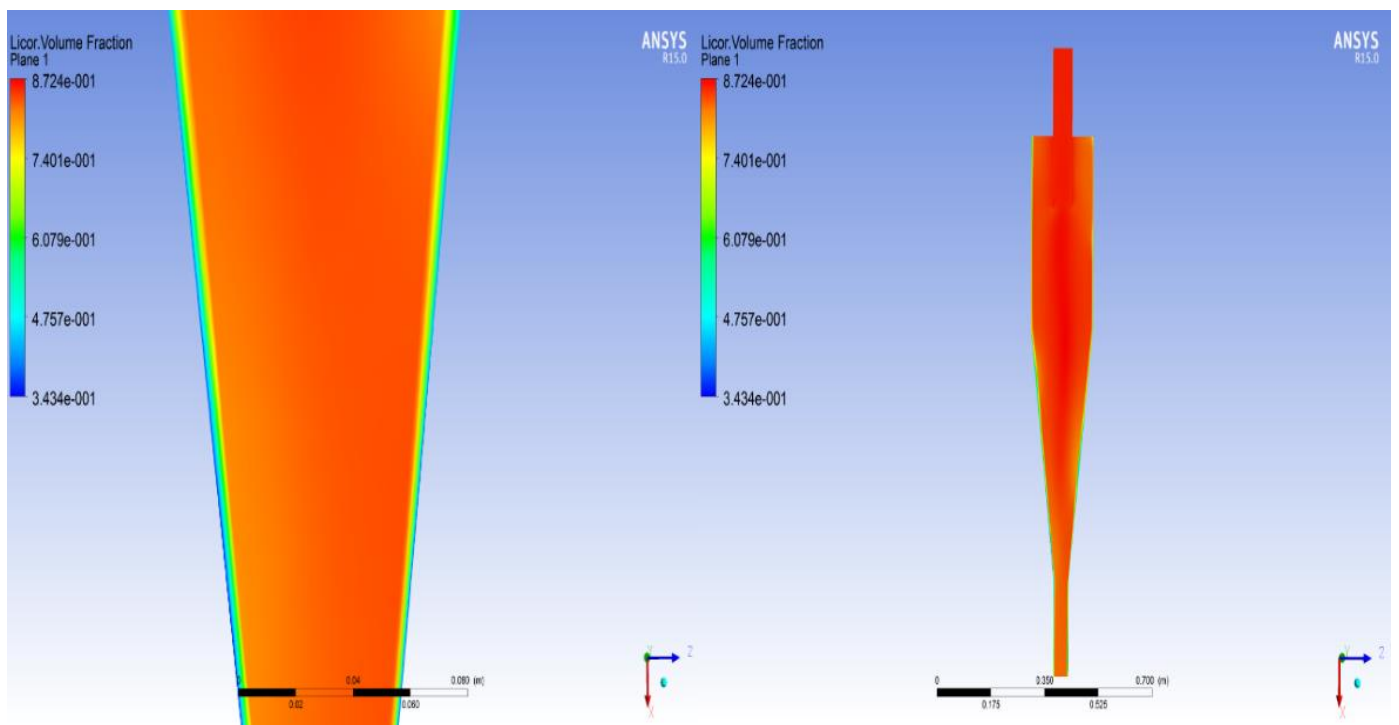

Figura 6 - Perfil de fração volumétrica do licor cáustico.

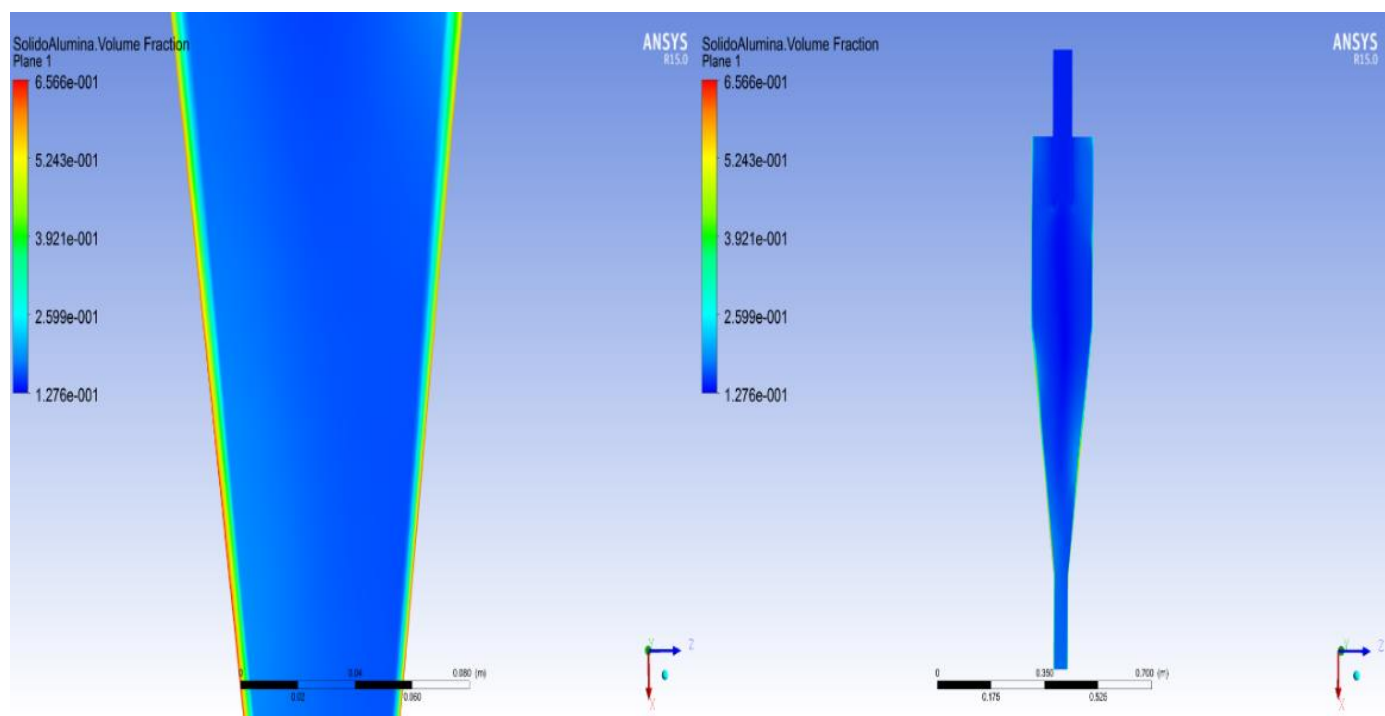

Figura 7 - Perfil de fração volumétrica da alumina.

A Tabela 3 compara a eficiência total obtida por meio da simulação realizada com a eficiência total experimental de uma planta de produção de alumina. Observa-se, para as condições operacionais do teste $\mathrm{C}$, a qual consiste em uma maior pressão de alimentação, uma melhor eficiência de separação de partículas. No entanto, deve-se analisar simultaneamente a eficiência granulométrica, mostrada no Tabela 4, mostrando melhores eficiências de separação de partículas de maiores diâmetros no teste $\mathrm{C}$, e melhor desempenho com partículas de menores diâmetros no teste $\mathrm{E}$, sabendo que estas últimas são desejadas em sua maioria na saída de topo do hidrociclone. No entanto, o modelo para a obtenção de eficiência granulométrica apresentou erros maiores para partículas sólidas de diâmetros extremos em relação ao diâmetro médio. 
Tabela 3 - Dados experimentais e simulados obtidos

\begin{tabular}{|c|c|c|}
\hline Teste & Eficiência Experimental (\%) & Eficiência Simulada (\%) \\
\hline A & 54,47 & 55,26 \\
\hline B & 51,27 & 55,54 \\
\hline C & 56,09 & 56,10 \\
\hline D & 43,70 & 55,20 \\
\hline E & 38,63 & 55,30 \\
\hline F & 37,12 & 55,49 \\
\hline
\end{tabular}

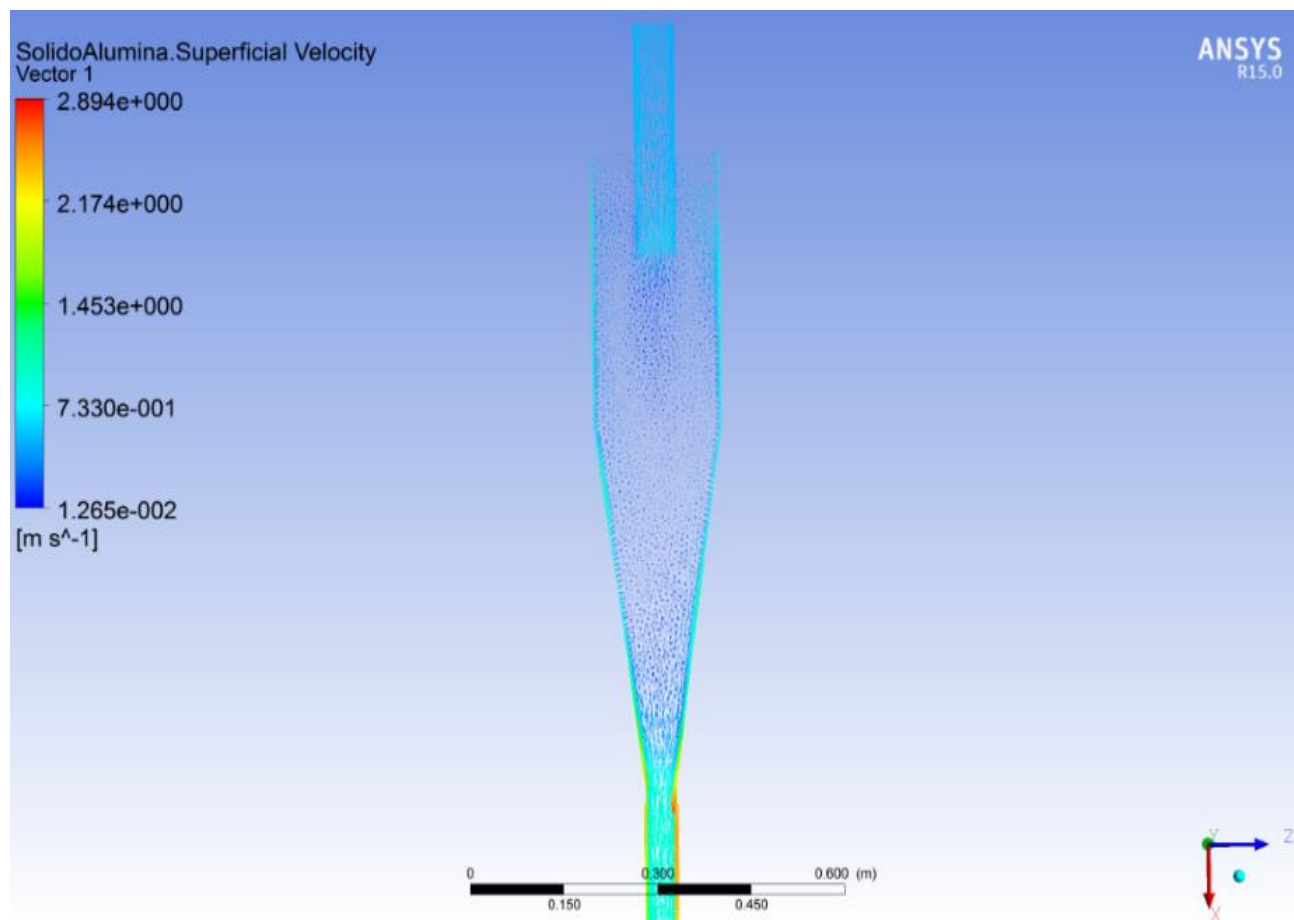

Figura 8 - Vetores de velocidade superficial da alumina.

Tabela 4 - Eficiências granulométricas simuladas e experimentais

\begin{tabular}{|c|c|c|c|c|c|c|c|}
\hline Resultado & $\begin{array}{c}\text { Diâmetro } \\
\text { (Micra) }\end{array}$ & $\begin{array}{c}\text { Teste A } \\
(\%)\end{array}$ & $\begin{array}{c}\text { Teste B } \\
(\%)\end{array}$ & $\begin{array}{c}\text { Teste C } \\
(\%)\end{array}$ & $\begin{array}{c}\text { Teste D } \\
(\%)\end{array}$ & $\begin{array}{c}\text { Teste } \mathrm{E} \\
(\%)\end{array}$ & $\begin{array}{c}\text { Teste F } \\
(\%)\end{array}$ \\
\hline Previsto & \multirow{2}{*}{20} & 44,54 & 42,38 & 44,16 & 43,6 & 37,41 & 47,73 \\
\hline Experimental & & 10,1 & 10,4 & 20,7 & 18,8 & 15,1 & 9,5 \\
\hline Previsto & \multirow{2}{*}{44} & 48,01 & 48,16 & 48,41 & 48,36 & 44,41 & 54,68 \\
\hline Experimental & & 33,3 & 32 & 41,4 & 34,3 & 27,8 & 24,4 \\
\hline Previsto & \multirow{2}{*}{76} & 53,79 & 53,39 & 58,92 & 56,08 & 46,83 & 58,74 \\
\hline Experimental & & 48,6 & 45,1 & 55,2 & 45,8 & 35,8 & 33,9 \\
\hline Previsto & \multirow{2}{*}{92} & 56,41 & 56,18 & 66,91 & 60,3 & 49,05 & 60,98 \\
\hline Experimental & & 64,8 & 61,8 & 66,9 & 55,4 & 45,1 & 44,1 \\
\hline Previsto & \multirow{2}{*}{124} & 63,54 & 66,77 & 69,58 & 66,42 & 58,14 & 64,52 \\
\hline Experimental & & 75,5 & 74,6 & 74,6 & 63,6 & 50,1 & 50,8 \\
\hline
\end{tabular}




\section{CONCLUSÕES}

A simulação realizada foi validada com dados experimentais de uma planta industrial de produção de alumina, corroborando a aplicação do modelo utilizado ao sistema de separação de partículas.

A análise do sistema a partir da eficiência global apresentou-se de forma satisfatória e permitiu observar um melhor desempenho para as condições operacionais do teste $\mathrm{C}$, para uma geometria fixa. Por outro lado, a observação dos valores obtidos para eficiências individuais legitimou o acréscimo do desempenho do hidrociclone à medida que o diâmetro de partículas aumenta, de forma menos acentuada frente ao experimental. Isto indicou o teste $\mathrm{C}$ com uma melhor performance de separação para partículas de maiores diâmetros, e o teste E apresentou melhores resultados na atuação do equipamento para partículas de menor diâmetro, as quais desejam ser obtidas em sua maioria na saída de topo do hidrociclone. Todavia, a previsão das eficiências granulométricas exibiram uma diferença entre os valores previstos por meio de simulação e valores experimentais, principalmente para partículas com diâmetros extremos de operação, para os quais o modelo deve ser melhorado.

\section{AGRADECIMENTOS}

Os autores agradecem ao incentivo financeiro provido pelo CNPq/UFCG e ao Laboratório de Experimentação Numérica de Processos (LENP) da Unidade Acadêmica de Engenharia Química - Universidade Federal de Campina Grande.

\section{REFERÊNCIAS}

ANSYS-CFX release 15.0 Reference Manual.

CULLIVAN, J. C.; WILLIAMS R. A.; DYAKOWSKI T. e CROSS C.R. New understanding of a hydrocyclone flow field and separation mechanism from computational fluid dynamics. Elsevier Minerals Engineering v.17, p.651-660, 2004.

SHUETZ S.; MAYER M. B.; PIESCHE M. Investigation on the flow and separation behavior of hydrocyclones using computational fluid dynamics. Elsevier Miner. Process. v.73, p.229237, 2004.

SILVA, C. Desempenho de Hidrociclones na Classificação de Hidrato. Campina Grande, 2006. 108p. Dissertação de Mestrado Universidade Federal de Campina Grande, Paraíba.

STEPHENS D.W. e MOHANARANGAM K. Turbulence model analysis of flow inside a hydrocyclone. Seventh International Conference on CFD in the Minerals and Process Industries, 2009. Melborne, Australia.

WANG B. e YU A. B. Numerical study of particle-fluid flow in hydrocyclones with different body dimensions. Miner. Eng. v. 19, p.1022-1033, 2006. 